\title{
MEMORIAL SOBRE A TRAJETÓRIA ESCOLAR BÁSICA DE MARCELA SILVA GUIMARÃES
}

\author{
Marcela Silva Guimarães ${ }^{1}$
}

Resumo: O presente texto trata do memorial sobre a trajetória escolar de Marcela Silva Guimarães, ex-integrante do Programa Conexões de Saberes. Tem como objetivo apresentar os passos percorridos desde o início da educação básica até a entrada à UFPA e quais os principais entraves de estudantes das comunidades populares adentrarem o ensino superior público. A memória foi usada como principal referência para construção do material. Em seus resultados, apresenta os esforços individual e coletivo para que de fato a educação seja uma questão de direito e não de privilégio de poucos.

É um pouco complicado fazer um pequeno resumo de minha vida pelo tanto de coisas que passei meus medos, angústias, alegrias e até mesmo desesperos, mas a parte ruim não merece ser lembrada. Chamo-me Marcela Silva Guimarães, filha de Maria de Fátima Silva Guimarães e Severino Ramos de Menezes Guimarães, pais que sempre me respeitaram, me amaram, me ajudaram e me apoiaram em tudo que passei. Meu pai é anajaense e minha mãe nasceu no Rio Aramã. Eles conheceram aqui em Breves, ambos vieram pra cá com perspectivas de vida melhor. Tenho duas irmãs mais velhas e dois irmãos mais novos: Bárbara, Bel, Daniel e Severino Neto.

Comecei estudar aos 4 anos na escola Santo Agostinho, porque era a escola mais perto de casa. De lá tenho várias recordações, confesso que são para mim recordações ruins porque me lembro com clareza da régua de madeira que a professora usava caso a gente não acertasse a tabuada; minha mãe também usava esse método em casa. Hoje a entendo, mas naquela época a achava muito cruel, com o tempo percebi o quanto ele é importante para mim, ela foi a pessoa que mais me deu força pra estudar e se hoje estou aqui agradeço primeiro a Deus depois a ela. Tempos depois fui para escola Miguel Bitar, eu tinha muita preguiça de estudar e de novo todos pegavam no meu pé. A diretora conseguiu o número do telefone do trabalho da minha mãe só pra contar todos os meus passos. Na sétima série reprovei como castigo minha mãe me trocou de escola, fui estudar na escola Estevão Gomes. Lembro que chorei muito quando soube, mas aquele ano foi muito importante pra mim, me fez perceber que eu precisava mudar meus conceitos sobre estudar Acadêmica de Pedagogia da Universidade Federal do Pará, Campus Breves, e-mail:
conexoesmulticampi@yahoogrupos.com.br

Revista PET Interdisciplinar e Programa Conexões /UFPA On-line. Ed. Especial - 2017, BELÉM/ PA - ISSN 2447-097X 
de fato. Cursei o Ensino Médio na Escola Elizete Nunes, no turno da noite, pois precisava conseguir um emprego, éramos cinco filhos e o salário dos meus pais era o suficiente, apesar de seus esforços. Passei então, a trabalhar de dia e estudar a noite, no início até cochilava em sala de aula, mas depois acostumei.

Tentei a primeira vez o vestibular no ano de 2002, foi uma das piores decepções da minha vida não ver o meu nome naquela lista, eu resolvi que em 2003 só iria trabalhar. No mesmo ano perdi o emprego e minha mãe disse que era melhor eu aproveitar pra estudar pro vestibular de 2004. No início foi isso que fiz, mas em janeiro comecei a trabalhar novamente, continuei estudando pra valer e fiz as três fases do vestibular. O meu patrão se chamava Carlos Alberto, ele também me ajudou muito, pois me liberava pra estudar, sempre me incentivando. Depois da última fase, a grande expectativa: o resultado, já havia fracassado uma vez e ia ficar arrasada se acontecesse novamente. Passava o tempo todo me informando quando sairia o resultado e ficando nervosa a cada dia. Era sábado de carnaval e surgiram comentários que o trio ia revelar o nome dos aprovados, fiquei aflita, mas a informação era falsa, em seguida anunciaram que no domingo de manhã sairia o listão dos aprovados. Lembro que dormi pouco e mesmo de ressaca pulei cedinho da cama, tomei um banho e me preparei para o resultado, minha mãe estava comigo na mesa da cozinha muito ansiosa também. Algum tempo depois começaram a anunciar, fiquei nervosíssima ouvindo o nome de pessoas conhecidas, chegou à letra $\mathrm{M}$ e meu nome foi o primeiro a ser chamado, foi uma festa em casa, meus pais me abraçaram e ficaram muito felizes.

Esse dia foi especial, me senti muito feliz não só por ter passado no vestibular, mas também por conseguir dar esse grande orgulho aos meus pais. Minha mãe sempre diz que seu sonho é ver todos os seus filhos na universidade e como eu sempre fui a mais desajeitada na escola, felizmente tinha conseguido fazer a minha parte. Após escutar meu nome saí para comemorar. Lembro que fui pra frente da escola na qual havia estudado e os professores perguntavam surpresos se eu havia passado. Durante a festa, me sujaram de tudo e até deixei cortarem o meu cabelo. O curso de Pedagogia não era o curso dos meus sonhos, mas meu sonho era entrar na universidade pra poder ser alguém na vida como diz a minha mãe. Sempre tive vontade de fazer o curso de Educação Física e ainda quero fazer quando puder, mas como aqui em Breves só havia as opções dos Cursos de Pedagogia e Letras, optei por Pedagogia, curso regular, uma vez que meu emprego era em empresa privada e era complicado conciliar os dois.

Revista PET Interdisciplinar e Programa Conexões /UFPA On-line. Ed. Especial - 2017, BELÉM/ PA - ISSN 2447-097X 
Hoje, mais do que nunca sei que fiz a coisa certa, pois meu curso é muito interessante, nele já descobri e percebi coisas que talvez nunca entendesse fora da Universidade. A escola passa a ser nossa segunda casa, dela ficam grandes recordações boas e ruins que influenciam muito na nossa vida adulta, cabe ao professor incentivar o aluno a crescer enquanto profissional. Apesar de aprender a gostar a pouco tempo desse curso tenho consciência de que ele me ajudou bastante na ampliação dos meus conhecimentos e hoje tenho um imenso prazer em aprender o que ele tem a me oferecer. Em nosso curso conseguimos entender a realidade da nossa educação e infelizmente não são todos os docentes que se esforçam para mudar esse quadro.

Como já estagiei várias vezes tive a oportunidade de ver de perto esse oficio. Vi educadores que não evoluíram sua prática pedagógica, mas também pude observar o empenho de alguns educadores tentando melhorar a nossa educação, tentando colocar ao máximo possível o que aprendemos em nossa vida acadêmica. Mesmo os que ainda não passaram por uma universidade, procuram fazer seu papel de educador, infelizmente às vezes por falta de recursos não podem fazer um trabalho melhor.

Reconheço que é muito bela a arte de educar, você saber que pode ajudar muitas crianças a crescer como pessoas, ajudar até mesmo no lado pessoal do seu aluno, e é gratificante saber que estamos fazendo um belo trabalho. O verdadeiro professor é aquele que mesmo com todas as dificuldades que a educação enfrenta, faz a sua parte, cuida dos seus alunos como se fossem seus próprios filhos e se sente feliz em saber que está contribuindo para formação deles, querendo sempre o melhor para cada um. No segundo ano da universidade já não estava mais trabalhando, dois meses depois engravidei e graças a Deus continuei tendo o apoio de meus pais. Continuei em casa e eles me ajudaram muito durante minha gravidez e meu filho é muito amado por mim é por toda a minha família. Seu nome é Kaio Rafael e hoje está com 11 meses. Todas as coisas ruins que passei são compensadas hoje por ele e minha família e a paz que Deus me deu e se eu já tinha objetivos na vida, aumentaram $100 \%$ depois que ele nasceu.

Em julho do ano passado passei a fazer parte do Projeto Conexões de Saberes. Durante esses 6 meses que faço parte do corpo desse projeto tive várias experiências marcantes, tanto pra minha vida pessoal, quanto para minha vida acadêmica. Tive a oportunidade de conhecer o projeto e sua importância, sua permanente luta por seus objetivos, devido aos obstáculos enfrentados.

Tivemos a oportunidade de trazer o Cursinho Popular para Breves. Fizemos uma pesquisa das pessoas que realmente necessitavam desse projeto e assim conseguimos perceber como 
realmente anda a realidade do nosso município. Fizemos todo o Projeto e conseguimos pô-lo em prática. Fomos atrás de professores que realmente nos estenderam a mão, pois as aulas que davam não eram remuneradas. Dentre estes educadores cito alguns: Roberta Amaral, Jorci Cunha, Flozinado Pureza, Antônio Pereira, Elinalva e seu esposo Jorge, entre outros. Foi gratificante ver aquelas pessoas que não tinham recurso de pagar um cursinho serem beneficiadas com o nosso esforço. Tive a oportunidade de participar de vários Fóruns e Seminários como o Seminário Local do Projeto Conexões.

Durante o evento pude conhecer bem mais o Projeto e seus objetivos. Infelizmente não pude participar do Seminário Nacional, pois sinto que foi uma grande perda de conhecimento.

Participei de várias reuniões do Fórum Acadêmico Popular. Tive a oportunidade de estudar o Grêmio Estudantil, conhecer seus objetivos e normas. Participei do Plano territorial de desenvolvimento Sustentável do arquipélago do Marajó o qual achei muito importante ajudar na construção desse projeto, pois o assunto discutido é o nosso Marajó, conhecendo bem mais a fundo a nossa realidade e dando a minha parcela de contribuição.

Na realidade, depois que passei a fazer parte do Conexões, passei também a me interessar por assuntos da universidade, inclusões sociais etc e aprendi a gostar mais do meu curso e fazer parte da UFPA ( o qual já havia até pensado em desistir).

O programa Conexões de Saberes foi um grande passo dado com esse tema: Acesso e permanência de Estudante de Origem Popular nas Universidades. (Achei tão interessante que esse é o meu tema do TCC). Percebemos que realmente há uma imensa dificuldade da massa de origem popular entrar na universidade e isso é um caso de extrema preocupação, pois a universidade pública é a única esperança da maioria das pessoas de terem o nível superior e superar a desigualdade social. Um absurdo o que está acontecendo em Breves, apenas 44 alunos foram selecionados para $3^{\circ}$ fase do PSS, os critérios são diferentes da nossa realidade e com isso a nossa educação vai para o lixo.

Esse é um pequeno trecho de minha vida pessoal, profissional e acadêmica.

Revista PET Interdisciplinar e Programa Conexões /UFPA On-line. Ed. Especial - 2017, BELÉM/ PA - ISSN 2447-097X 